withdrawn in cases in which from long compression the resiliency of a lung has been destroyed and the organ rendered incapable of filling by expansion in more or less degree the vacuum created. But in such cases, also, the condition is, I think, cardio-vascular, not pulmonary; it is a cardiac rather than pulmonary paresis, as Sir B. W. Richardson suggested and Sir James Barr recalls.

But, etiology apart, Dr. Williams has done good service in calling attention afresh to this state and it is to be hoped that the hiatus in text-books to which he has referred will now be filled. I am, Sirs, yours faithfully,

Upper Berkeley-street, W., Dec. 16th, 1907. ALEXANDER MORISON.

\section{PUBLIC VACCINATION IN OLDHAM.}

\section{To the Editors of THE LANCET.}

SIRS, - A representative meeting of Oldham medical men have had under consideration the proposed terms of appointment of a public vaccinator for the township of Oldham, and they wish to point out the following facts in regard to the proposed appointment:-

A short time ago the guardians thought of appointing such an officer at a fixed salary of $£ 500$ per annum, and binding him to devote the whole of bis time to the duties of the office, and this proposal received the approval of Dr. S. W. Wheaton, the Local Government Board inspector. This proposal, however, was not carried out because the Local Government Board then reduced the fees for successful public vaccination from $5 s$. per case to $2 s$. $6 d$. per case, but the said officer to be paid the minimum scale of fees-namely, 2s. 6d. per case-allowed by the Local Government Board, and to be allowed $£ 15$ per annum for a central vaccinating station, and also to be allowed the necessary dressings. Taking as a basis the amount of public vaccination done by the present interim pub'ic vaccinators during the six months ending Sept. 30th, 1907, we are advised that the proposed officer could at the most earn $£ 200$ per annum. Matters are now even worse than this, for under the recent Act of Parliament increased facilities for obtaining exemption orders have been provided and possibly as a result of this the amount of public vaccination in the town has decreased, we are informed, to 33 cases during the month of November and it is quite possible that this decrease may continue still further; but taking November as a basis the proposed officer would earn $£ 69$ inclusive of $1 s$. per case for notification and visit per annum, an amount which we consider entirely inadequate for a pro. fessional man devoting his whole time to the duties of the office and so sacrificing the principal portion of his professional life.

At our meeting it was resolved that no such proposed appointment could be satisfactory unless the guardians were prepared to guarantee a minimum salary and that salary should be at least $£ 350$ per annum. A deputation from us was also appointed and has waited upon a number of the guardians and pointed out the above facts, but not mentioning our proposed minimum of $£ 350$ per anne $m$ without any satisfactory result, although the guardians present were individually of opinion that the proposed office should have a living wage but they would not fix what amount tbat should be. At our adjourned meeting it was resolved that this statement be drawn up and sent to all the local members of the profession so that they be adrised not to apply for the proposed office until the guardians have amended their proposed terms of appointment by including a guaranteed minimum salary.

We are, Sirs, yours faithfully,

JAMHS CoRns, Chairman.

Oldham, Dec. 14th, 1907. Frank RADCLIFFE, Hon. Sec.

\section{THE LATE DR. A. MACTIER PIRRIE.}

To the Editors of TH LaNChT.

SIRS, - In your appreciative obituary notice of the late Dr. A. Mactier Pirrie, whose untimely death is greatly to be deplored, I see you state that he travelled through the Bahrel-Ghazal Province of the Soudan. This is not the case.
Dr. Pirrie was never farther south than Barboi wood station which is near the mouth of Zeraf river, a short distance south of Taufikia on the White Nile. His work was done on the banks of the latter, at the American Mission on the Sobat, and amongst the Burnn people who occupy a littleknown district between the White Nile and the Abyssinian frontier. I think it very likely that Dr. Pirrie acquired the infection which unhappily proved fatal to him in the Sennar province. He entered this district after a somewhat remarkable journey through Burun territory and it is here that cases of kala-azar have been occurring quite recently. With the exception of a single case discovered by Dr. Neave in 1903 this disease has not hitherto come under notice in the Soudan, and, so far as is definitely known, Dr. Pirrie is the first European to fall a victim to it. The work of Captain Cummins, and latterly of Captain Bousfield, both of the Egyptian Medical Service, has shown, however, that it occurs with some frequency in certain districts, and I have recently met with the parasite in splenic smears sent from two cases terminating fatally at Wad Medani on the Blue Nile.

Dr. Pirrie was an enthusiastic observer, and for so young a man proved himself a remarkably good explorer, while bis handling of the shy and wild native tribes amongst whom he penetrated seems to have been characterised by much skill and tact. It may be interesting if I record a single incident of his expedition which occurred at Renk on the White Nile. The British inspector shot a duck which fell into a backwater of the Nile, known to be haunted by at least one very large and man-eating crocodile. A small native boy plunged into the water and swam out to retrieve the bird. He was noticed to be in difficulties and without a moment's hesitation Dr. Pirrie ran out of his tent bareheaded, entered the river and made a gallant though futile attempt to rescue the boy who had been seized with cramp. This brave act very nearly resulted in Dr. Pirrie acquiring sunstroke, for the affair happened during the hot part of the day. The story was told me by another British inspector and the incident was never mentioned by Dr. Pirrie. It will illustrate the type of man whose services we have lost and whose name must be added to the long list of those whom science can claim as martyrs.

\section{I am, Sirs, yours faithfully,}

ANDREW BALFOUR, M.D. Edin.,

Gordon College, Khartoum, Dec. 3rd, 1907

\section{THE NEEDS OF LONDON MEDICAL STUDENTS.}

To the Editors of THW LANCET.

Sins,-Your editorial article under this heading in last week's issue of your paper seems to me to be open to the charge of disingenuousness - to use the mildest term which occurs to me-in that part of it particularly which refers to concentration. You appear to base your view that the London medical student is handicapped in his struggle for a degree on the argument that because there is a multiplicity of medical schools his studies are "disorderly." You go on to state that "this was recognised four years ago by all the London medical schools" and " the principle of coopperation for the preliminary medical studies adopted by the medical faculty." You speak of the "scheme of amalgamation" and the "concentration scheme" as if this had remained a constant quantity in all these four years, and you blame the Senate by implication for its resolution that the "scheme had proved abortive." Finally, and very surprisingly, you find in the fact that Professor Starling was elected, by a majority of 11 in a poll of 239, the day after that resolution was made known, and consequently when the question had become a chose jugée and thereby no longer before the Faculty at all, ground for the statement, which ends your article, that "the Faculty shows by its votes that its members are in no way opposed to the concentration of the preliminary medical studies."

I think it would be easy to controvert every one of these statements. I shall, however, confine my remarks to your criticism of the action of the Senate in this matter. It certainly could not be gathered from your narrative that the scheme of concentration at the date of the recent election 
differed very materially from the scheme of "tour years ago"; how materially your readers may judge when they are informed that the scheme had been progressively whittled down from a project for universal concentration in one centre with buildings and endowment to cost $\$ 375000$, and a contemplated yearly entry of 350 students, to the suggestion that the University should provide accommodation with the $£ 70,000$ subscribed for the students of two schools whose combined yearly entry of internal students averages 28. Sir Arthur Rüoker, in your issue of Nov. 30th, forcibly points out that "it cannot be honestly said that on this capital it is possible to establish an institute such as that for which the subscriptions were given. It would have been a real breach of faith with the subscribers to attempt it." The history of the transition-which you wholly ignore-is as follows and to my mind completely justifies the action of the Senate.

Two years ago, under the active guidance of the dean of the Faculty of Medicine, and with no symptoms of dissent from the Faculty which he controls so admirably, the scheme was modified to include the foundation by the University of three centres for preliminary medical education, of which one, estimated "to accommodate with comfort a yearly entry of 100 medical students," has already been fully started and a second is on the eve of starting with equal accommodation. The Senate having thus provided for nearly two-thirds of the number of students originally contemplated was faced with the certainty that only about three-tenths of this number of students would come under concentration-centres. It was further demonstrated that simultaneously with the change of plan and the withdrawal of the larger schools subscriptions to the fund had entirely ceased. The provision under these conditions of yet another centre was clearly ridiculous; its necessity had throughout been con. tingent upon the demand exceeding the accommodation already provided at the two centres incorporated in the University (vide "appeal" of 1905). You yourself use the argument that an unnecessary multiplication of schools promotes "disorderliness of studies" and yet the University is blamed by you for not creating at great expense a new school to compete with its own depleted centres and with at least six other constituent schools which have refused concentration.

You omit also to mention in explanation of the action of the Senate that the decision to which they have come was conditioned by the terms on which the site had been offered. These were that an adequate sum of money, estimated at $£ 130,000$, should be subscribed to the fund before Dec. 31st, 1907, when the option of the site was to lapse. A large body of members of the Senate and of the Faculty of Medicine hoped that there might be saved from the inevitable wreck of the whole scheme that part of it which contemplated helping research. It was felt by this section that, to use the words of the statute which had been the germ of the whole movement, "common courses of instruction in the preliminary and intermediate studies" had been provided by the University far in excess of the demand for such teaching at its two centres; and that the "third centre" which was no longer required for this purpose might very well be devoted to research work, provision for which had been prominently demanded in the original appeal, in response to which all the money in hand had been subscribed. The saving of this part of the scheme had been rendered impossible by the action of the party which you support, and I hope that they and you are proud of the result.

$$
\text { I am, Sirs, yours faithfully, }
$$

London, W., Dec. 18th, 1907.

k. Graham LitThe.

* * The facts are well known. We support no party ; we are concerned with obtaining for the London student a medical degree at his University. We disagree with many of Dr. Graham Little's conclusions, but do not, therefore, call him disingenuous. He is, however, mild compared with one gentleman who has addressed us upon the subject of our untruthfulness, gross partisanship, and power of making mischief. Of course there are members of the Faculty who are opposed to the concentration scheme. In the very article where we are supposed to have concealed this obvious fact we allude to it over and over again, and seriously how could any sane person deny it? It is clear that our closing words mean that the Faculty as a whole has in no way declared against concentration in such a way that the quegm tion must be considered permanently closed.-ED. L.

\section{To the Editors of THE LANCET.}

SIRs, - When is this futile anomaly of medical titles to be abolished? Is anything to come of discussion this time? It is, "Send for the "Doctor." "Good morning, "Doctor." "Oh, yes, 'Mr.' Jones is my 'Doctor.'" Surely the stupidity of the convention needs no comment. There is at least one town, supporting several practising "physicians and surgeons," where the only individual who has the undeniable right to call himself "doctor" on his visiting cards is a retired American dentiat. Everyone knows the perplexity of the intelligent foreign $\mathbf{r}$ over the absurd distinctions of address in our profession in this country. There is one partial remedy which should meet with little opposition. The University of London might be clear-sighted enongh to institute a degree for Conjoint men of mature age much on the lines of that of St. Andrews. A man of 40 years is unlikely to improve much by the additional letters save his amour propre, but that means a deal to many, and many would go to the trouble and expense of trying for it where the provincial degree would seem hardly so desirable.

The crux of the whole matter, of course, is that the "haves" are the powers that be and they do not see why they should level up the "have-nots," though they freely admit the ethical justice of the demand, and may $I$ add that those very " haves" are always most scrupulous in addressing the said Mr. Jones as "Doctor Jones" when they are called into consultation with him ?

Dec. 11th, 1907

I am, Sirs, yours faithfully,

$$
\text { A " HAVE-NO'T." }
$$

\section{To the Editors of THE LANCET.}

SIRs, - I was glad to see you devote a leading article to the needs of London medical students, but somewhat disappointed that you did not say more upon the subject. You say. "No suggestion has been put forward to meet the admitted dis. abilities ..... \&c.," but really do not offer any yourself. The question, to my mind, has two aspects quite distinct from each other-viz.: (1) the prefix of "Doctor" and (2) the suffix of "M.D." Every registered medical practitioner is known to the public as a doctor and is given this designa. tion as the proper means of describing him. In ordinary common law "custom," if often enough repeated, has the force of law, and so every medical practitioner has the legal right to the title of "doctor"; as a matter of fact, the law cannot prevent anyone who pleases from using this title. This right appears to have been lost sight of. The medical man should therefore help himself; he should put the prefix "Dr." upon his door-plate (as the M.B. already does) he should address all other practitioners as "Dr." The societies, the medical journals, \&c., should always give him this title, as is done in the colonies and elsewhere than in England.

As regards the degree of M.D., it may be noted that London, with its population of nearly 7,000,000, has only one degree-granting corporation, whereas Liverpool, Manchester, Leeds, Birmingham, Edinburgh, Glasgow, Áberdeen, Dublin, Oxford, Cambridge, and Durham, with a combined population of $3,500,000$, have 12 degree-granting bodies-an unfair proportion. If London had universities in the same proportion she would have 24 universities granting the degree of M.D. instead of only one as at present.

As a solution of the M.D. aspect of the question, without in any way interfering with the London University medical degree, I would suggest the following. The Archbishop of Canterbury still retains his power of granting an M.D. degree (M.D. Lambeth) to persons who are already legally qualified practitioners. Now why cannot the Medical Council induce him to confer this degree upon every registered medical practitioner who applies for it? The fee charged would produce a large income which might be devoted to charitable purposes, after defraying expenses, if he saw fit. A somewhat similar procedure exists with regard to a Member of Parliament-he cannot resign his seat, so he "accepts the Chiltern Hundreds."

Dec. 16th, 1907 .
I am, Sirs, your faithfully, SYMPATHISER. 